\title{
Preexposure and Postexposure Prophylaxis of Rabies With Adeno-Associated Virus Expressing Virus-Neutralizing Antibody in Rodent Models
}

OPEN ACCESS

Edited by:

Xiaohui Zhou,

Fudan University, China

Reviewed by:

Chunfu Zheng,

University of Calgary, Canada

Hervé Bourhy,

Institut Pasteur, France

*Correspondence:

Ling Zhao

zling604@yahoo.com

Huiping Zhou

742683192@qq.com

Specialty section:

This article was submitted to

Virology,

a section of the journal

Frontiers in Microbiology

Received: 29 April 2021

Accepted: 28 July 2021

Published: 19 August 2021

Citation:

Huang F, Ren M, Pei J, Mei H, Sui B,

Wu Q, Chai B, Yang $R$, Zhou $M$,

Fu ZF, Zhou $H$ and Zhao L (2021)

Preexposure and Postexposure

Prophylaxis of Rabies With Adeno-Associated Virus Expressing

Virus-Neutralizing Antibody in

Rodent Models.

Front. Microbiol. 12:702273.

doi: 10.3389/fmicb.2021.702273

\author{
Fei Huang ${ }^{1,2}$, Meishen Ren ${ }^{1,2}$, Jie Pei ${ }^{1,2}$, Hong Mei, ${ }^{1,2}$, Baokun Sui ${ }^{1,2}$, Qiong $\mathrm{Wu}^{1,2}$, \\ Benjie Chai ${ }^{1,2}$, Ruicheng Yang ${ }^{1,2}$, Ming Zhou ${ }^{1,2}$, Zhen F. Fu ${ }^{1,2}$, Huiping Zhou ${ }^{3 *}$ and \\ Ling Zhao ${ }^{1,2 *}$
}

'State Key Laboratory of Agricultural Microbiology, Huazhong Agricultural University, Wuhan, China, ${ }^{2}$ Key Laboratory of Preventive Veterinary Medicine in Hubei Province, College of Veterinary Medicine, Huazhong Agricultural University, Wuhan, China, ${ }^{3}$ School of Basic Medicine, Hubei University of Science and Technology, Xianning, China

Rabies, a fatal disease in humans and other mammals, is caused by the rabies virus (RABV), and it poses a public health threat in many parts of the world. Once symptoms of rabies appear, the mortality is near $100 \%$. There is currently no effective treatment for rabies. In our study, two human-derived RABV-neutralizing antibodies (RVNA), CR57 and CR4098, were cloned into adeno-associated virus (AAV) vectors, and recombinant AAVs expressing RVNA were evaluated for postexposure prophylaxis after intrathecal injection into RABV-infected rats. At 4 days post-infection with a lethal dose of RABV, $60 \%$ of the rats that received an intrathecal injection of AAV-CR57 survived, while $100 \%$ of the rats inoculated with AAV-enhanced green fluorescent protein (EGFP) succumbed to rabies. Overall, these results demonstrate that AAV-encoding RVNA can be utilized as a potential human rabies postexposure prophylaxis.

Keywords: rabies viruses, adeno-associated virus, virus-neutralizing antibody, preexposure prophylaxis, postexposure prophylaxis, rodent models

\section{INTRODUCTION}

Rabies is a fatal disease caused by the rabies virus (RABV), and it is estimated that rabies causes 59,000 deaths annually, mostly in developing countries (Jackson, 2003; Fooks et al., 2014). RABV is a neurotropic virus of the genus Lyssavirus in the family Rhabdoviridae, with a single-strand negative-sense RNA genome and five structural proteins (N, P, M, G, and L; 
Schnell et al., 2010). Rabies has a varied incubation time. Since its early symptoms are usually mild, rabies infection may not be recognized until it invades the central nervous system (CNS; Kelly and Strick, 2000). The replication of RABV may maintain at a low level in muscle cells (Charlton and Casey, 1981; Yamaoka et al., 2013) after infection by a bite from a rabid animal. It subsequently invades the peripheral nervous system (PNS) by retrograde axonal transport and replicates in the spinal cord's motor neurons before entering the CNS (Katz et al., 2017).

Postexposure prophylaxis recommended by the World Health Organization (WHO) includes wound washing at the RABV exposure site, rabies immune globulin (RIG) administration, and rabies vaccine administration (World Health Organization, 2018). However, once the virus invades the CNS, rabies is nearly $100 \%$ fatal (Ugolini and Hemachudha, 2018).

Although facing a major challenge to cure patients from advanced rabies, researchers have made several attempts to treat symptomatic RABV (Smith et al., 2019). In 2004, a patient with rabies symptoms survived after applying a therapeutic approach called the Milwaukee protocol (Willoughby et al., 2005). Nevertheless, its effectiveness is controversial as no less than 31 failures have been reported using the same protocol (Zeiler and Jackson, 2016). Wang et al. (2011) investigate the direct injection of a recombinant RABV vaccine strain expressing GM-CSF (LBNSE-GMCSF) into the brains of mice 4-6 days after they had been infected with a lethal dose of wild-type RABV. Studies by Chen et al. (2013) and Huang et al. (2015) demonstrated that in mice, intracranial injection of parainfluenza virus 5 (PIV5) expressing RABV glycoprotein elicited virusneutralizing antibodies, enhanced the blood-brain barrier (BBB) permeability, and promoted the survivor ratio of mice infected with a lethal dose of RABV. A live RABV vaccine, on the other hand, is unlikely to be authorized for therapeutic use in human rabies patients. Most recently, de Melo et al. (2020) showed that a combination of RABV-neutralizing antibodies (RVNA) RVC20 and RVC58 could rescue symptomatic mice post RABV infection by concomitantly administration of RVNA in the CNS through intracerebroventricular infusion, sheding a light for an effective rabies therapy in humans.

Adeno-associated virus (AAV) has been used as a vector for gene therapy for many years (Flotte et al., 1993; MartinezNavio et al., 2019). AAV could become the vector of choice for many gene therapy applications due to its simple structure, unique biology, and a lack of known disease associations (Naso et al., 2017; Rabinowitz et al., 2019). The number of clinical trials of AAV-based gene therapies initiated annually increased by more than four times from 2014 to 2017 (Kuzmin et al., 2021). Clinical data from more than 3,000 patients over more than 20 years suggest that AAV-based gene therapy is safe and efficient. Recently, U.S. Food and Drug Administration approved two AAV-based therapies, namely Luxturna for a rare inherited retinal dystrophy and Zolgensma for spinal muscular atrophy (Kuzmin et al., 2021). The number of agents using AAV9 capsids for CNS delivery has increased since 2015, indicating the potential use of gene therapy for CNS diseases (Samaranch et al., 2019; Taghian et al., 2020).
In this study, we evaluate the efficiency of preexposure and postexposure prophylaxis of rabies with AAV expressing two RVNAs, CR57 and CR4098, in rodent models, both of which have presented a protective role during postexposure prophylaxis in a hamster model (Bakker et al., 2005; Marissen et al., 2005; Goudsmit et al., 2006). Our data show that delivery of AAV encoding RVNA CR57 can effectively reduce the mortality of RABV-infected rodents and may have applications for both preexposure and postexposure prophylaxis of rabies in future.

\section{MATERIALS AND METHODS}

\section{Viruses, Cells, Antibodies, Plasmids, and Animals}

CVS-B2c is a laboratory-adapted RABV strain derived from the CVS-24 virus by passaging in BHK-21 cells (Wang et al., 2005). DRV-Mexico, isolated from a dog in Mexico, is a wild-type RABV strain (Dietzschold et al., 2000). BSR cells (a clone of BHK-21 cells) were maintained in DMEM containing $10 \%$ fetal bovine serum (FBS). Human embryonic kidney 293T cells (HEK-293T) were cultured in RPMI 1640 medium (Mediatech, Herndon, VA, United States) containing 10\% FBS. RABV $\mathrm{P}$ protein-specific monoclonal antibody was prepared in our laboratory, as previously described (Sui et al., 2020). Fluorescein isothiocyanate (FITC)-conjugated antibodies against the RABV-N protein were purchased from Fujirebio (Malvern, PA). RABV CVS-B2c genomic backbone plasmid and helper plasmids were prepared in our laboratory, as previously described (Tian et al., 2016). The pAAV-CMV-eGFP and helper plasmids were obtained from Dr. Gang Cao, Huazhong Agricultural University, China (Liu et al., 2020). In addition, 6-week-old female BALB/c mice and Sprague-Dawley rats were purchased from the Center for Disease Control of Hubei Province, Wuhan, China. All animal experiments were approved by the Scientific Ethics Committee of Huazhong Agricultural University (permit number HZAURA-2019-009). The animal experiments involving the infection with RABV were carried out in the animal facility with ABSL-2 level at Huazhong Agricultural University.

\section{Construction of the Recombinant AAV Vectors}

Three AAV9 plasmids were constructed, each containing a CMV promoter followed by a signal peptide and an anti-rabies immunoglobulin CR57 or CR4098 (Bakker et al., 2005; Goudsmit et al., 2006); EGFP replaced the immunoglobulin and served as a control. The resulting plasmids were referred to as AAV-CR57, AAV-CR4098, and AAV-EGFP. Recombinant AAVs were produced by transfection of HEK-293T cells with the selected AAV vector, helper1, and helper2 plasmids at a ratio of 1:1:1. Cells and culture supernatants were harvested at $36 \mathrm{~h}$ posttransfection (hpt) and centrifuged for $5 \mathrm{~min}$ at $1,000 \mathrm{~g}$. The cell pellets were resuspended in RPMI 1640 and then subjected to four rounds of freeze/thaw in a dry ice bath and a $37^{\circ} \mathrm{C}$ 
water bath. The suspensions were centrifuged for $10 \mathrm{~min}$ at $10,000 \mathrm{~g}$ to pellet the cell debris and then filtered through a $0.22-\mu \mathrm{m}$ membrane. The AAV copy number was assessed by real-time PCR. Primers were designed based on the known sequence information. F: 5'-CGGCCTCAGTGAGCGA-3', R: 5'-GGAACCCCTAGTGATGGAGTT-3' (Meng et al., 2013).

\section{Confirmation of mAb Expression in Cells by Western Blotting}

Human embryonic kidney 293T cells were infected with AAVs at a multiplicity of infection (MOI) of 5 and incubated at $37^{\circ} \mathrm{C}$ for 4 days. Then, the cell culture medium was collected and enriched by protein A/G agarose beads (Smart Lifesciences, SM1505) and eluted with elution buffer (Sui et al., 2020). Next, the supernatants were collected, and a $1 \times$ SDS loading buffer was added. Then, samples were separated on $12 \%$ SDS polyacrylamide gels (SDS-PAGE) and transferred to PVDF membranes (Bio-Rad). Subsequently, the membranes were blocked with TBST supplemented with $5 \%(w / v)$ nonfat dry milk for $3 \mathrm{~h}$ and then incubated with horseradish peroxidase (HRP)-conjugated rabbit anti-human IgG (Boster, Wuhan, China, BA1070) for $1 \mathrm{~h}$ at $37^{\circ} \mathrm{C}$. Finally, the blots were developed by a BeyoECL Star kit (Beyotime, P0018A). Images were taken by an Amersham Imager 600 (GE Healthcare) imaging system.

\section{Virus-Neutralizing Antibody Assay}

Virus-neutralizing antibody titers were measured by using a fluorescent antibody virus neutralization (FAVN) assay as previously described (Luo et al., 2019). Briefly, quadruplicate samples of 3 -fold serial dilutions of the test serum and the standard serum were prepared in 96-well microplates. The standard serum $(2 \mathrm{IU} / \mathrm{ml})$ was obtained from Nancy Laboratory for Rabies and Wildlife in Malzéville, France. One hundred focus-forming units (FFU) of CVS-11 suspension were aliquoted into each well. The plates were incubated for $1 \mathrm{~h}$ at $37^{\circ} \mathrm{C}$, and then $2 \times 10^{4} \mathrm{BSR}$ cells were added to each well. The microplates were then incubated for $72 \mathrm{~h}$ at $34^{\circ} \mathrm{C}$. The cells were then fixed for $30 \mathrm{~min}$ with $80 \%$ ice-cold acetone and stained with FITC-conjugated antibodies against the RABV $\mathrm{N}$ protein. The fluorescence was assessed under an IX51 fluorescence microscope (Olympus, Tokyo, Japan). The VNA titers were recorded as international units per milliliter using the standard curve from the reference serum.

\section{Mouse Immunization and Challenge Test}

Six-week-old female BALB/c mice were randomly divided into three groups and immunized with $10^{12}$ vector genome AAVs via an intramuscular (i.m.) route. At the indicated time points post-immunization, serum was collected from the peripheral blood samples to quantify the VNA titers. The mice received a challenge infection with $30 \mu \mathrm{l}$ of $50 \times$ mouse $50 \%$ lethal doses $\left(\mathrm{LD}_{50}\right)$ CVS-24 intracerebrally (i.c.) 24 weeks after the primary immunization. Mice found to be moribund or lose more than $30 \%$ of their starting body weight were humanely euthanized.

\section{Construction and Rescue of the Recombinant RABV Expressing teLuc}

The recombinant RABV expressing teLuc (RABV-teLuc) was constructed based on the RABV CVS-B2c strain as described previously (Zhang et al., 2013). Briefly, the luciferase teLuc coding sequence flanked by BsiW I and Nhe I restriction sites was inserted between the coding sequences of RABV $G$ and $\mathrm{L}$ proteins to generate the plasmid pcDNA3.1-rB2c-teLuc. Notably, teLuc with a synthetic CTZ analog is more sensitive in rodent models than traditional luciferase (Yeh et al., 2017). For virus rescue, this plasmid in combination with helper plasmids expressing the $\mathrm{N}, \mathrm{P}, \mathrm{G}$, and $\mathrm{L}$ proteins was transfected into mouse neuroblastoma cells using Lipofectamine ${ }^{\mathrm{TM}} 2000$ (Invitrogen). The rescued recombinant RABV-teLuc virus was confirmed by direct fluorescence antibody assay (DFA) under an Olympus IX51 fluorescence microscope.

\section{Virus Titration}

Viral titers were determined by DFA. Briefly, BSR cells were infected with 10 -fold serial dilutions of the viruses in 96-well plates in quadruplicate. After incubation at $37^{\circ} \mathrm{C}$ for $48 \mathrm{~h}$, the cells were fixed with $80 \%$ acetone and then incubated with FITC-conjugated anti-RABV-N antibody for $1 \mathrm{~h}$ at $37^{\circ} \mathrm{C}$. Antigenpositive cells were visualized with an IX51 Olympus fluorescence microscope. Viral titers were calculated and are presented as the numbers of FFU/ml as previously described (Luo et al., 2019).

\section{Measurement of teLuc Luciferase Activity}

Twenty-four mice were randomly divided into eight groups, with three mice in each group. Seven groups of mice were i.m. inoculated with $6 \times 10^{4} \mathrm{FFU}$ RABV-teLuc in the right hind limb, and one group of mice were i.m. injected with $100 \mu \mathrm{l}$ saline as a mock control. During the 3-9 days post-infection (dpi), every one of the seven groups of infected mice was chosen every other day to collect their brains and spinal cords. The brains and spinal cords from the mock group were also collected at $9 \mathrm{dpi}$ and stored at $-80^{\circ} \mathrm{C}$. Brain and spinal cord samples from each mouse were separately placed in $2 \mathrm{ml}$ tubes containing $1 \mathrm{ml}$ DMEM to be homogenized at $4^{\circ} \mathrm{C}$ for $10 \mathrm{~min}$. Subsequently, the supernatants were individually collected and mixed with $0.01 \mu \mathrm{mol}$ diphenylterazine (DTZ; Med Chem Express) after centrifuging at $8,000 \mathrm{~g} 4^{\circ} \mathrm{C}$ for $10 \mathrm{~min}$. The luciferase expressed by RABV-teLuc was detected using a GLOMAX 20/20 Luminometer (Promega). Supernatants from the infected cell cultures were mixed with $0.01 \mu$ mol DTZ, and the luciferase activity was determined as described above.

\section{Bioluminescence Imaging of Animals Infected With RABV-teLuc}

Twelve 6-week-old female BALB/c mice were randomly divided into four groups, with three mice in each group. Three groups of mice were i.m. inoculated with $50 \times$ mouse $\mathrm{LD}_{50}$ of RABVteLuc, and the mock group was i.m. inoculated with the same volume of DMEM. One of the three groups of infected mice was taken every other day for intrathecal injection with $0.3 \mu \mathrm{mol}$ 
DTZ per mouse 3-5dpi. In addition, the mock group was inoculated with $0.3 \mu \mathrm{mol}$ DTZ per mouse. Five minutes after injection with DTZ, the mice in each group were imaged by an IVIS Lumina III (PerkinElmer).

Eighteen 6-week-old female rats were randomly divided into six groups, with three rats in each group. Five groups of rats were i.m. inoculated with $50 \times$ rat $\mathrm{LD}_{50}$ of RABV-teLuc. One group of rats was i.m. injected with $100 \mu \mathrm{l}$ saline as a mock control. During 3-7 dpi, each of the five groups of RABVinfected rats was taken every other day for intrathecal injection with $0.3 \mu \mathrm{mol}$ DTZ per rat. The mock group was also inoculated with $0.3 \mu \mathrm{mol} \mathrm{DTZ}$ per rat. Five minutes after injection with DTZ, the rats in each group were imaged by an IVIS Lumina III.

\section{Production and Purification of Rat RIG}

Three rats were i.m. immunized with $10^{7} \mathrm{FFU}$ of RABV vaccine strain LBNSE-dOG in the right hind legs (Pei et al., 2019). Four weeks later, the rats were sacrificed, and their blood was collected. The blood samples were placed at $37^{\circ} \mathrm{C}$ for $1 \mathrm{~h}$ and then at $4^{\circ} \mathrm{C}$ for $12 \mathrm{~h}$ before centrifuging at $3,000 \mathrm{~g}$ for $10 \mathrm{~min}$. The serum was diluted 10 -fold with $20 \mathrm{mmol} / \mathrm{L} \mathrm{Na}_{3} \mathrm{PO}_{4}$ and filtered with a $0.45-\mu \mathrm{m}$-pore-size filter. The filtered serum was then loaded onto a column of protein A\&G agarose beads (Smart Lifesciences, SM1505) and eluted with elution buffer. The antibodies were concentrated using a centrifugal filter with a protein concentration tube with Molecular Weight Cut Off $50 \mathrm{kD}$ (Millipore) and then suspended in natural saline to preserve the antibody. VNA titers were measured by FAVN.

\section{AAV Administration in Animals}

$\mathrm{BALB} / \mathrm{c}$ mice ( $n=10$ /group) were i.m. inoculated with $50 \times$ mouse $\mathrm{LD}_{50}$ DRV-Mexico in the right hind limb. The mice were inoculated via i.c. with a dose of $40 \mu \mathrm{l}$ of $2.5 \times 10^{10}$ vector genomes $/ \mu \mathrm{l}$ (v.g./ $\mu \mathrm{l}$ ) of AAV-CR57 at 4,5 , and $6 \mathrm{dpi}$, or intranasally (i.n.) with a dose of $20 \mu \mathrm{l}$ of $5 \times 10^{10} \mathrm{v} . \mathrm{g} . / \mu \mathrm{l}$ of AAV-CR57 at $4 \mathrm{dpi}$, or intravenously (i.v.) with a dose of $100 \mu \mathrm{l}$ of $1 \times 10^{10} \mathrm{v.g} . / \mu \mathrm{l}$ of AAV-CR57 at $4 \mathrm{dpi}$. In addition, two groups of mice $(n=10)$ were inoculated with AAV-CR4098 or AAV-EGFP at 4 dpi.

The SD rats ( $n=12$ /group) were i.m. inoculated with $50 \times$ rat $\mathrm{LD}_{50}$ DRV-Mexico in the right hind leg. At $4 \mathrm{dpi}$, each group of rats received a single inoculation of $100 \mu \mathrm{l}$ of $4 \times 10^{10} \mathrm{v} . \mathrm{g} . / \mu \mathrm{l}$ AAV-CR57, or $100 \mu \mathrm{l}$ of $4 \times 10^{10}$ v.g./ $\mu \mathrm{l} \mathrm{AAV-EGFP,} \mathrm{or} 100 \mu \mathrm{l}$ of $4 \times 10^{10} \mathrm{v.g} . / \mu \mathrm{l}$ AAV-CR57 plus $20 \mathrm{IU} / \mathrm{kg}$ RIG or $100 \mu \mathrm{l}$ of $4 \times 10^{10}$ v.g./ $\mu \mathrm{l}$ AAV-EGFP plus $20 \mathrm{IU} / \mathrm{kg}$ RIG. Briefly, after induction of anesthesia, the rat's head was placed in a stereotactic frame and flexed in a prone position. The back of the neck was shaved, cleaned with $75 \%$ alcohol, and then injected with the indicated solutions into the cisterna magna as described previously (Samaranch et al., 2012).

\section{Western Blotting}

Brains were lysed in RIPA buffer (Beyotime, P0013D) mixed with $1 \times$ protease inhibitor cocktail (Roche). Brain lysates were separated on $12 \%$ SDS-PAGE gels and then transferred to PVDF membranes (Bio-Rad). The membranes were blocked with TBST supplemented with 5\% $(w / v)$ nonfat dry milk for
$3 \mathrm{~h}$ and then incubated with primary antibodies, including anti-RABV N protein (laboratory prepared, 1:5,000) or antiGAPDH (ProteinTech, 60004-1-Ig, 1:5,000), overnight at $4^{\circ} \mathrm{C}$. After rinsing, the membranes were incubated with HRP-conjugated goat anti-mouse IgG (Boster, Wuhan, China, BA1051) for $1 \mathrm{~h}$ at $37^{\circ} \mathrm{C}$ and then developed by a BeyoECL Star kit (Beyotime, P0018A). Images were taken by an Amersham Imager 600 (GE Healthcare) imaging system.

\section{Immunohistochemistry Analysis}

Brain specimens were fixed in $4 \%$ paraformaldehyde for $48 \mathrm{~h}$ at $4^{\circ} \mathrm{C}$ and then dehydrated in PBS supplemented with $30 \%$ sucrose for $48 \mathrm{~h}$ at $4^{\circ} \mathrm{C}$. The tissue sections were embedded in paraffin wax and mounted on slides, and the slides were heated to $60^{\circ} \mathrm{C}$, deparaffinized, and rehydrated in xylene and graded ethanol, heated for antigen retrieval, and treated with an endogenous peroxidase blocking solution. The sections were then incubated with primary anti-RABV $\mathrm{P}$ antibody (laboratory prepared, 1:500) overnight at $4^{\circ} \mathrm{C}$. Next, the sections were incubated with HRP-conjugated antirabbit secondary antibodies (BioPM, PMK-013-090, 1:200) for $30 \mathrm{~min}$, followed by two washes in PBS. After washing, the sections were incubated with diaminobenzidine (Servicebio, G1211) for color development and then photographed and analyzed using an XSP-C204 microscope (CIC).

\section{Statistical Analysis}

GraphPad Prism 8 (GraphPad Software, Inc., CA, United States) was used for data analysis. Unpaired two-tailed Student's $t$-test was used to analyze the statistical significance. Kaplan-Meier survival curves were used to determine the statistical significance of the survivor ratio in the challenge test. Statistically significant differences are represented as ${ }^{*} p<0.05,{ }^{* *} p<0.01,{ }^{* *} p<0.001$, and ${ }^{* * *} p<0.0001$; ns means no significant difference.

\section{RESULTS}

\section{Characterization of Recombinant AAVs Expressing Anti-RABV Antibodies}

To determine whether AAV-expressing antibodies can be used for preexposure and postexposure prophylaxis of rabies, the encoding sequences of two well-known RABV-specific virusneutralizing antibodies, CR57 and CR4098 (Bakker et al., 2005; Marissen et al., 2005), as well as EGFP (as a control), were cloned into the AAV9 vector. A schematic description of the construction of different recombinant AAVs (AAV-CR57, AAV-CR4098, and AAV-EGFP) is shown in Figure 1A. HEK-293T cells were infected with different AAVs at an MOI of 5, and VNA titers in the culture supernatants were monitored over 4 dpi. At 3 dpi, CR4098 and CR57 titers in the culture supernatants were equal to or greater than 0.5 international units $/ \mathrm{ml}(\mathrm{IU} / \mathrm{ml})$, which is the minimum protection level against RABV infection defined by the WHO (Figure 1B). The culture supernatants were collected and enriched at 4 dpi. Expression of the heavy chain and light chain was detected by Western blotting with HRP-conjugated rabbit anti-human IgG (Boster, Wuhan, China, 


\section{A

\begin{tabular}{|l|l|l|l|l|l|l|l|l|l|}
\hline 5' ITR & CMV \\
\hline
\end{tabular} \\ $\longleftarrow$ Heavy chain $\longrightarrow$ Light chain $\longrightarrow$ \\ Anti-RABV mAb coding sequence}

B

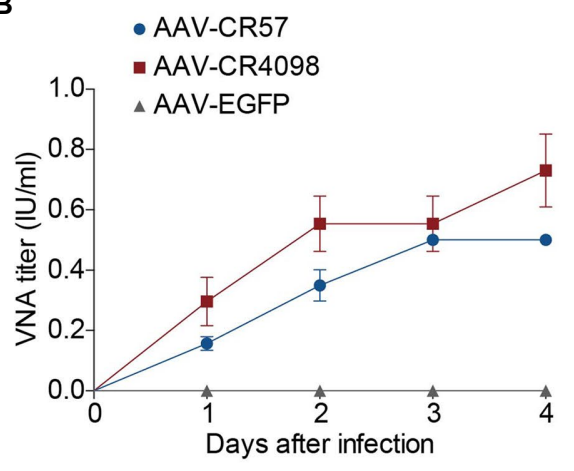

D

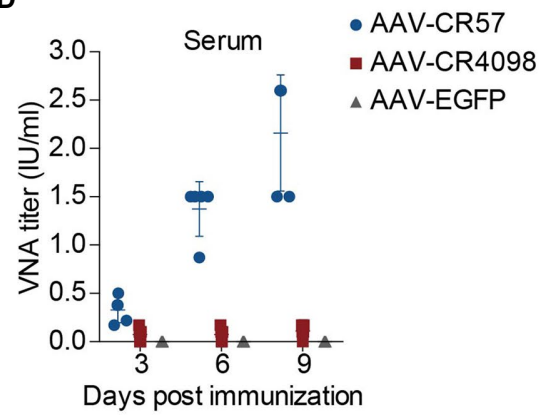

C

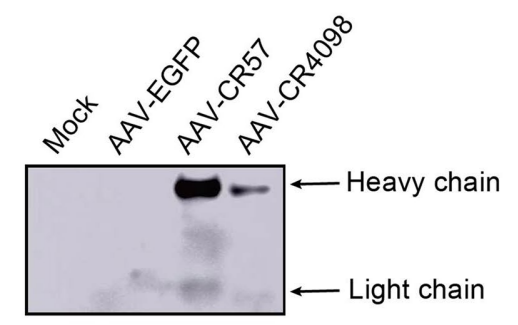

E

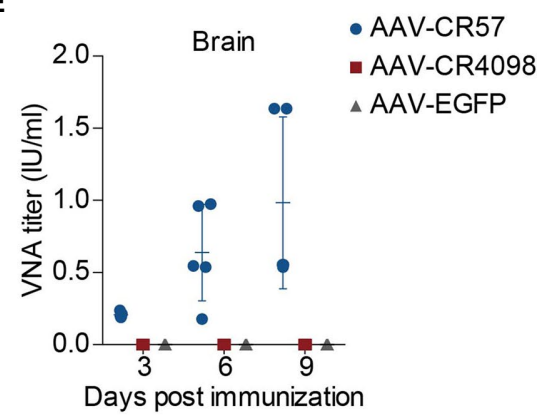

FIGURE 1 | Construction and characterization of recombinant adeno-associated viruses (AAVs) expressing rabies virus-neutralizing antibodies (RVNA). (A) A schematic diagram describing the construction of the AAV-RVNA vector. The AAV expression vector contains a CMV enhancer/promoter, a signal peptide (SP), and an anti-rabies virus (RABV) monoclonal antibody (CR57 or CR4098) sequence. (B) One-step growth curves for AAVs on HEK-293T cells at a multiplicity of infection (MOI) of 5 are shown. (C) Western blotting analysis of RVNA expression in HEK-293T cells infected with AAVs. (D) Groups of 6-week-old female BALB/c mice ( $n=5$ ) were i.c. inoculated with $10^{12}$ vector genome of AAVs. At the indicated time points post-inoculation, the serum (D) and brain (E) were collected, and the VNA titers in these samples were determined by using the fluorescent antibody virus neutralization (FAVN) test as described in the Materials and Methods.

BA1070). As shown in Figure 1C, the mAb expression of AAV-CR57 was much higher than that of AAV-CR4098 in HEK-293T cells. Therefore, we further evaluated the VNA levels generated by the AAVs in vivo. The AAVs were inoculated intracerebrally (i.c.) into $\mathrm{BALB} / \mathrm{c}$ mice; at each time point (3, 6 , and $9 \mathrm{dpi}$ ), mice were humanely sacrificed ( $n=5 /$ group), and the VNA levels in sera (Figure 1D) and brains (Figure 1E) were measured. The results showed that AAV-CR57 generated a protective level of VNA in mouse serum and brains post i.c. inoculation. However, mAb produced by AAV-CR4098 in the serum and the brain was almost undetectable.

\section{Intramuscular Immunization With AAV-CR57 Results in Long-Lasting Antibody Production in Mice}

Since AAV-CR57 and AAV-CR4098 can generate mAbs in vivo and in vitro, the effect of the AAVs on antibody production via i.m. inoculation was evaluated in a mouse model. Three groups of $\mathrm{BALB} / \mathrm{c}$ mice ( $n=12$ /group) were immunized, i.m. with $10^{12}$ vector genomes of AAV-CR57, AAV-CR4098, or AAV-EGFP. At indicated time points post-immunization, blood samples were collected, and VNA titers were measured using the FAVN test. The mice immunized with AAV-CR57 maintained significantly higher VNA titers than the AAV-CR4098-immunized mice at all the time points up to 60 weeks post-infection (wpi). The antibody levels in the mice reached a peak $(92 \mathrm{IU} / \mathrm{ml})$ at 24 wpi (Figure 2A).

Furthermore, the protective effect of AAVs against virulent RABV challenge was evaluated. At 24 wpi, all of the mice $(n=12)$ were i.c. challenged with $50 \times$ mouse $\mathrm{LD}_{50}$ of CVS-24 and then monitored for another 3 weeks (Figure 2B). All of the mice in the AAV-EGFP group succumbed to rabies within 12 days, while $100 \%$ of the mice immunized with AAV-CR57 were protected from the lethal challenge compared with only $66 \%$ of the AAV-CR4098 group. These results demonstrated 

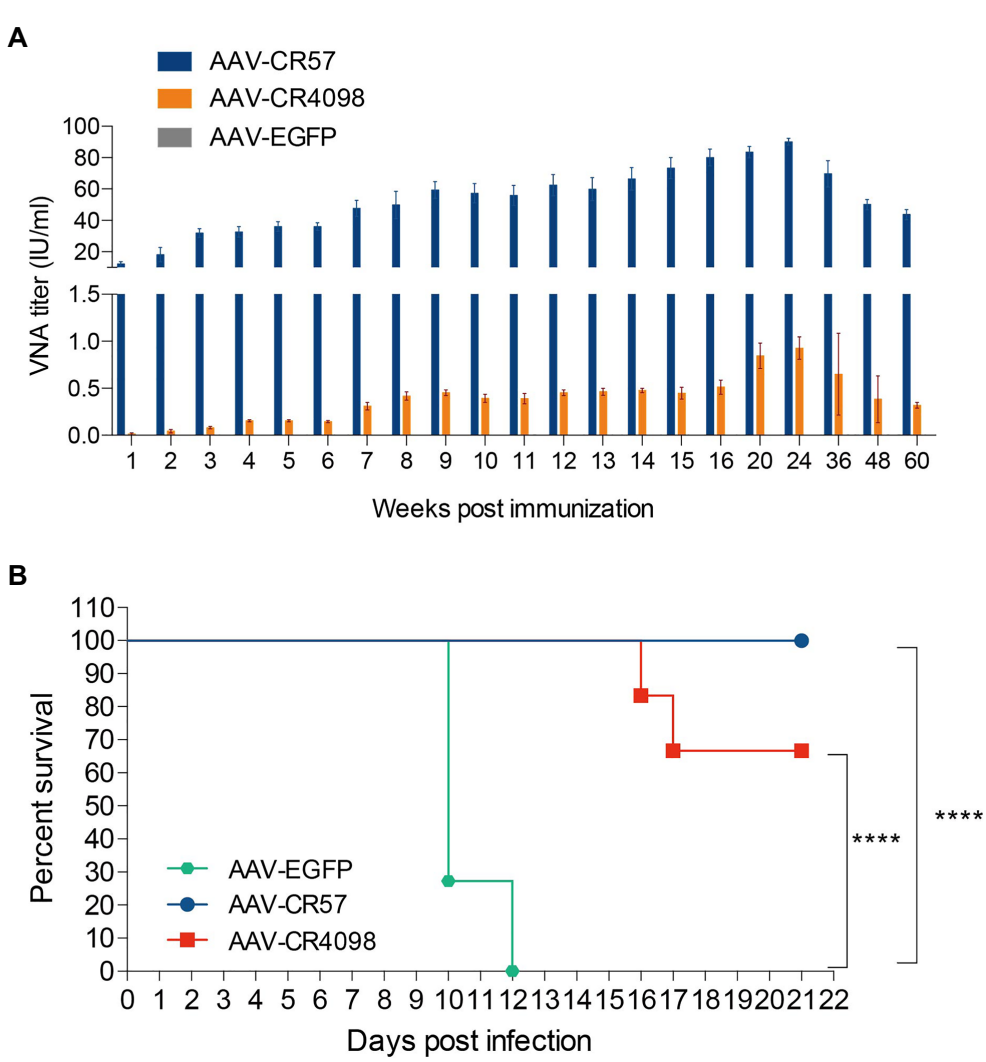

FIGURE 2 | Preexposure prophylaxis of rabies by using AAVs expressing RVNA. (A) RVNA levels in serum following the administration of AAV expressing CR57, CR4098, or EGFP. Groups of 6-week-old female BALB/c mice $(n=10)$ were i.m. immunized with a $10^{12}$ vector genome of AAV. The serum was collected from the peripheral blood samples at the indicated time points post-immunization, and the VNA titers were quantified by the FAVN test. (B) At 24 weeks post-primary inoculation, the mice $(n=12)$ were i.c. challenged with $50 \times$ mouse $L D_{50}$ CVS-24 and were then observed daily for 3 weeks. The number of survivors in each group was recorded. ${ }^{* \star *} p<0.0001$.

that preexposure immunization with AAV-CR57 could result in sustained antibody production and provide longterm protection.

\section{In vitro Characterization of RABV-teLuc and Trace the Migration Dynamic of RABV With RABV-teLuc in a Mouse Model}

To track the migration dynamic of RABV in mice, a recombinant RABV encoding teLuc was constructed. As shown in Figure $\mathbf{3 A}$, the coding sequence of teLuc was inserted into the genome of RABV CVS-B2c strain between the $G$ and $\mathrm{L}$ genes, resulted in RABV-teLuc. The growth curves of RABV-teLuc in BSR cells demonstrated that RABV-teLuc replicated as efficiently as the parent virus CVS-B2c (Figure 3B) and that the expression of luciferase in RABV-teLuc-infected BSR cells (MOI of $0.001,0.01,0.1$, and 1 ) at $24 \mathrm{~h}$ postinfection (hpi) was dose-dependent (Figure 3C). Post i.m. infection with RABV-teLuc in the mouse hind legs, the migration dynamic in the mouse bodies was monitored by a bioluminescence imaging system (Figure 3D). The results showed that RABV-teLuc was detected as early as 3 dpi in the spinal cord of infected mice. From 3 to $5 \mathrm{dpi}$, RABV migrated from the spinal cords to the brain. At 5 dpi, RABV in one of the mice $(n=3)$ was found to invade the brain. These data were consistent with other detection methods like RT-qPCR and RPA-CRISPR (Ren et al., 2021a) and provided the basis for choosing the appropriate time point to deliver AAV-CR57 into the RABV-infected mice.

\section{Protection of AAV-CR57 by Different Administration Ways in a Mouse Model}

To evaluate the therapeutic efficacy of AAV-CR57 in a rabies postexposure prophylaxis mouse model, mice were injected, i.m. with $50 \times$ mouse $\mathrm{LD}_{50}$ DRV-Mexico, and then treated with AAV-CR57, AAV-CR4098, or AAV-EGFP (via i.c., i.v., or i.n.) at $4 \mathrm{dpi} \quad(n=10)$. The results showed that intracerebral administration with AAV-CR57 at 4 dpi significantly improved the 3-week survival ratio of the infected mice (70\%) over those treated with AAV-EGFP ( $0 \%$; Figure 4A). In contrast, administration with AAV-CR57 by i.v. or i.n. route did not affect mouse survival (Figures 4B,C). However, inoculation with AAV-CR57 by i.c. at 5 and 6 dpi did not enhance the survival ratio of the infected mice over the negative control (Figure 4D). These data demonstrated that direct delivery of AAVs to the CNS no later than $4 \mathrm{dpi}$ is necessary for a therapeutic effect in RABV-infected mice. 
A

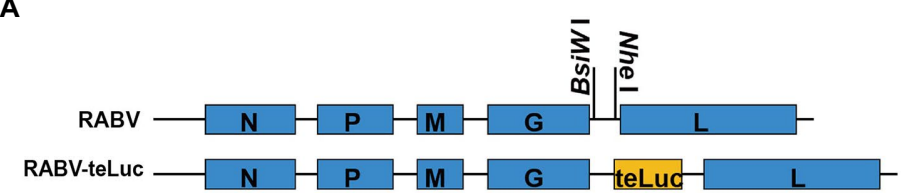

B

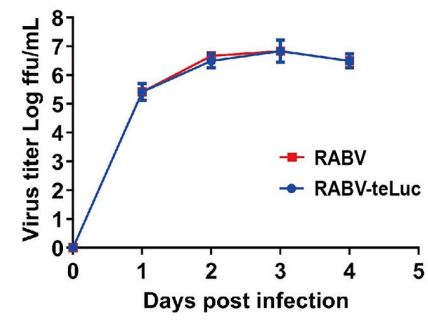

C

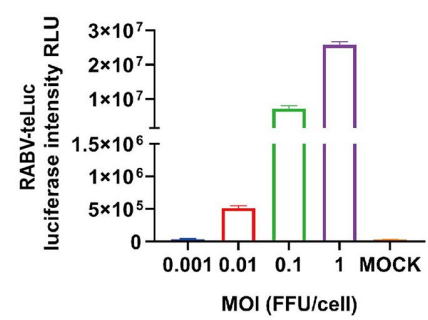

D

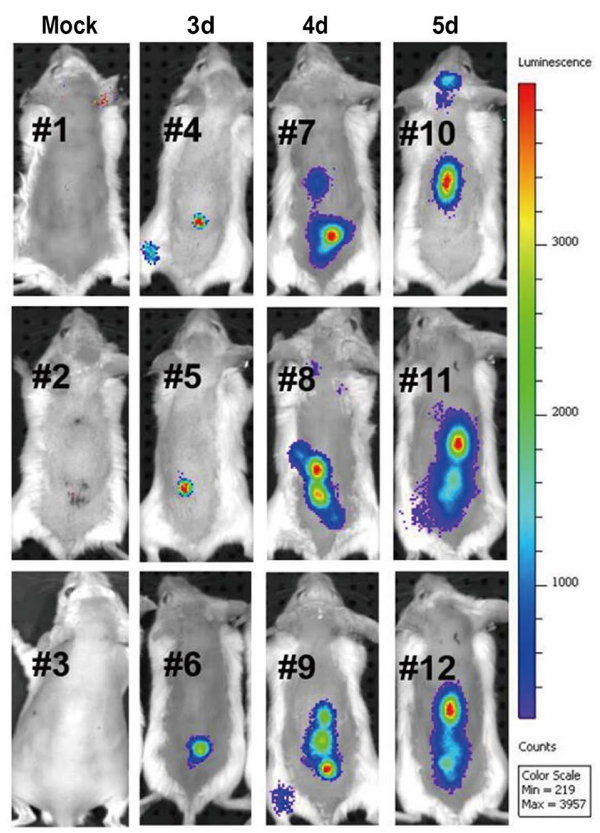

FIGURE 3 | The migration dynamics of RABV in mice post i.m. inoculation with a recombinant RABV expressing teLuc. (A) Schematic diagram showing the construction of recombinant RABV expressing teLuc, termed RABV-teLuc. (B) Single-step growth curves of RABV-teLuc and the parent virus in BSR cells infected at an $\mathrm{MOI}$ of 0.01. (C) Expression of teLuc in BSR cells infected with the indicated dose of RABV-teLuc at 24h post-infection (hpi). (D) Early detection of RABVteLuc infection in a mouse model. Twelve 6-week-old BALB/c mice were randomly divided into four groups, with three mice in each group. Three groups of mice were i.m. inoculated with $50 \times$ mouse $L D_{50}$ RABV-teLuc, and the mock group was i.m. inoculated with the same volume of DMEM. During 3-5 dpi, one of the three groups of RABV-infected mice was taken every other day for intrathecal injection with $0.3 \mu \mathrm{mol}$ diphenylterazine (DTZ) per mouse. The mock group was inoculated with $0.3 \mu \mathrm{mol}$ DTZ per mouse. The mice in each group were imaged by an IVIS Lumina III 5 min post-injection with DTZ.

Moreover, mouse brains were collected for viral quantification and immunohistochemical (IHC) analysis at 12 dpi $(n=3)$. IHC analysis showed no RABV-P-positive cells were observed in the cerebrum, cerebellum, or brainstem of the mice in the AAV-CR57 group. In contrast, significantly more RABVP-positive cells were observed in the AAV-EGFP group (Figure 5A). The viral protein in the mouse brains was further determined by Western blotting. As shown in Figure 5B, no RABV $\mathrm{N}$ protein was detected in the brains of mice treated with AAV-CR57, while RABV $\mathrm{N}$ protein was observed in the brains of mice treated with AAV-EGFP. Collectively, these results indicated that AAV-CR57 could protect mice from RABV infection.

\section{Protection of AAV-CR57 by the Intrathecal Route in a Rat Model}

According to the above results, the i.c. route was the most effective administration way of AAV-CR57 for rabies postexposure prophylaxis in the mouse model. However, it is not quite feasible to deliver AAV-CR57 to the rabies patient 
A

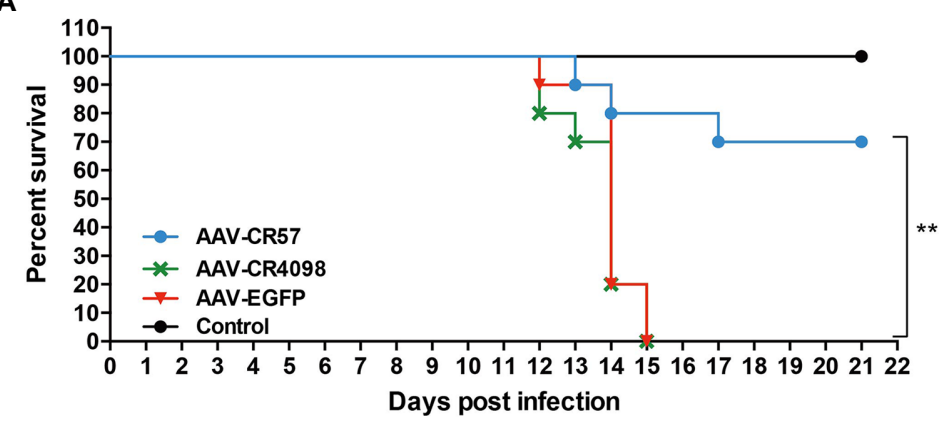

B

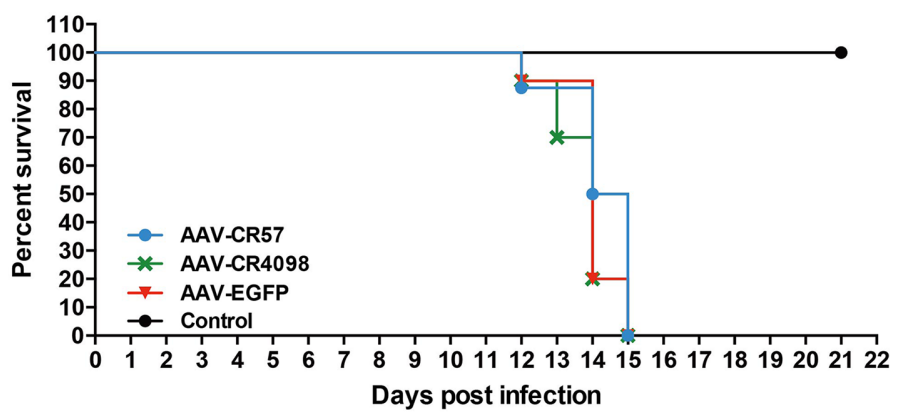

C

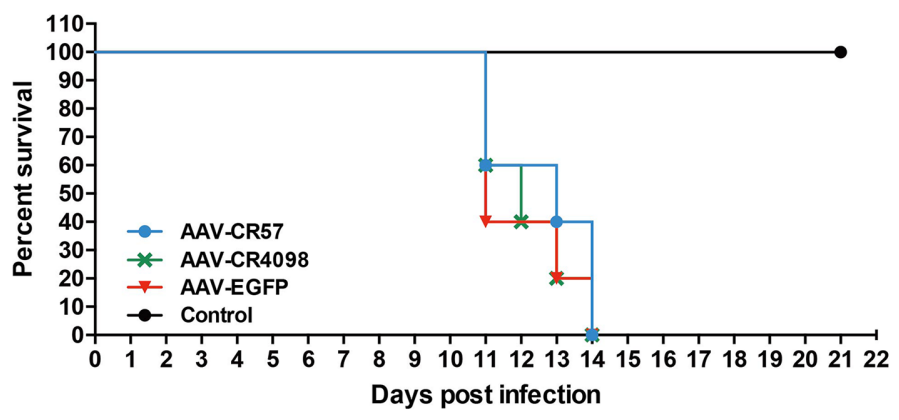

D

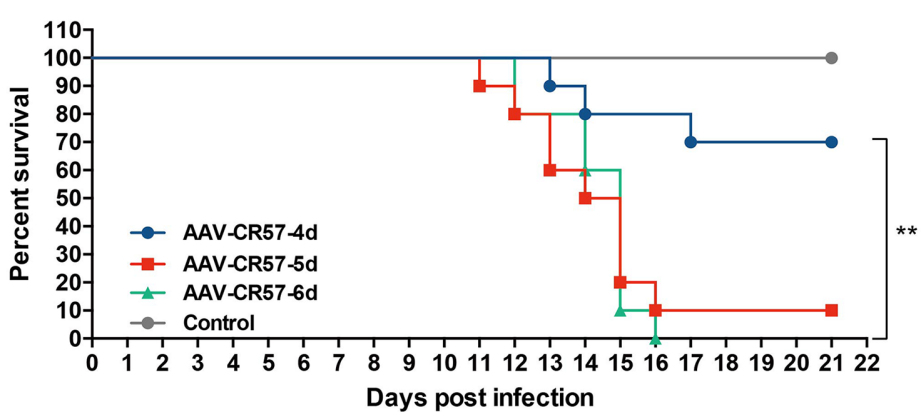

FIGURE 4 | Postexposure prophylaxis for rabies with AAV-expressing RVNA in a mouse model. Groups of 6-week-old female BALB/c mice ( $n=10)$ were i.m. injected with $50 \times$ mouse $L_{50}$ DRV. At 4 dpi, the mice was inoculated with $10^{12}$ vector genomes of different AAVs via i.c. (A), i.v. (B) or i.n. route (C). (D) Groups of 6-week-old female BALB/c mice $(n=10)$ were i.m. injected with $50 \times$ mouse $L D_{50}$ DRV and then i.c. inoculated with $10^{12}$ vector genomes AAV-CR57 at 4, 5 , and 6 days post-inoculation. The mock group was inoculated with the same volume of DMEM. Mice were monitored once daily for 3 weeks. The number of survivors in each group was recorded. Kaplan-Meier survival curves were used to determine the statistical significance of the survivor ratio. ${ }^{* *} p<0.01$.

by i.c. route. Alternatively, the intrathecal administration is commonly used in rabies treatment for humans (Basgoz and Frosch, 1998; Appolinario and Jackson, 2015). However, it is not easy to do the intrathecal injection in mice due to its tiny body size, and the rat model was therefore chosen to simulate the rabies treatment in humans by intrathecal 
A

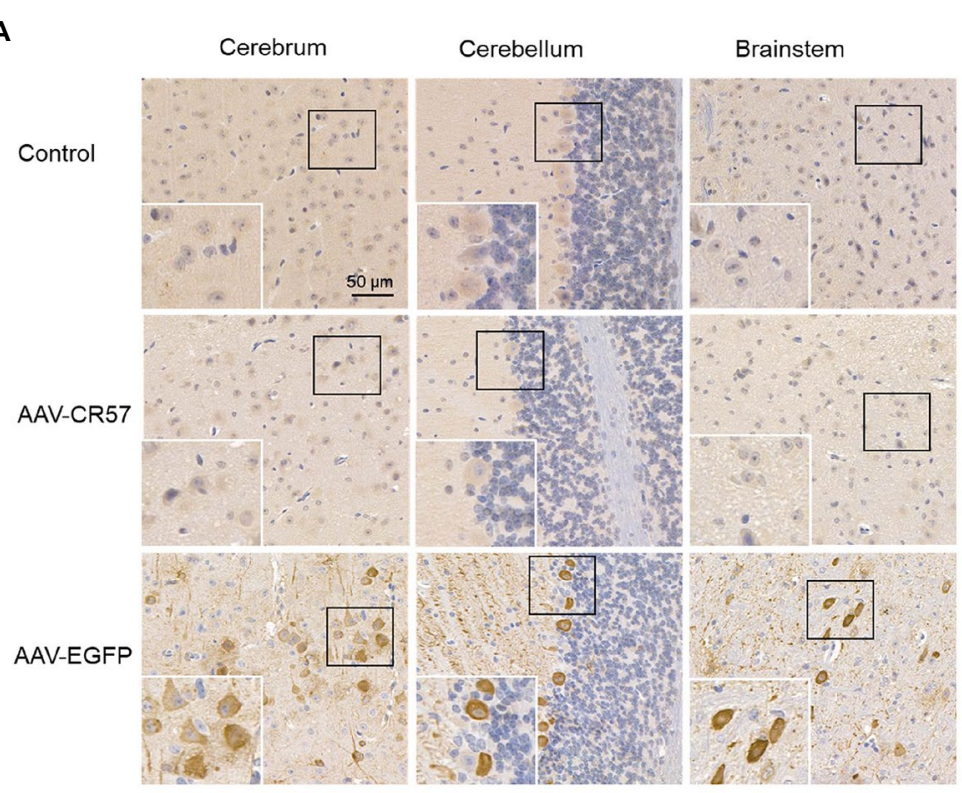

B

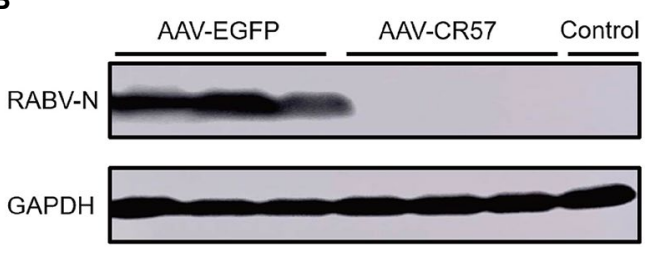

FIGURE 5 | Viral load in mouse brains post i.c. inoculation with AAVs expressing CR57 or EGFP. Groups of 6-week-old female BALB/c mice ( $n=10$ ) were i.m. injected with $50 \times$ mouse $L_{50}$ DRV and i.c. inoculated with $10^{12}$ vector genome of AAVs at the 4 dpi. The mock group was inoculated with the same volume of DMEM at 4 dpi. At 12 dpi, the brains were collected, and half of the brain was fixed, paraffin-embedded, sectioned, and analyzed by immunohistochemistry by staining with antibodies against RABV-P (A). Scare bar, $50 \mu \mathrm{m}$. The other half of the brain was analyzed for RABV-N levels by Western blotting (B).

administration in our study. Similarly, to trace RABV spread in rats post i.m. infection, bioluminescence imaging was performed in RABV-teLuc-infected rats. As shown in Figure 6, RABV-teLuc was detected as early as $3 \mathrm{dpi}$ in the spinal cord of infected rats $(n=3)$, and the viruses almost reached the brains of infected rats $(n=3)$ at $5 \mathrm{dpi}$ and invaded into the brains of infected rats $(n=3)$ at 6 and 7 dpi. Bioluminescence images of these rats indicated that $4 \mathrm{dpi}$ could be an appropriate injection window for rabies treatment in a rat model.

The RIG was widely used along with the rabies vaccine for rabies postexposure prophylaxis in humans, which provides rapid antibodies until the body can respond to the vaccines. Therefore, the strategy of delivering AAV-CR57 alone, AAV-CR57+rat RIG, AAV-EGFP+rat RIG, or AAV-EGFP alone to the CNS via intrathecal inoculation was assessed in a rat model, and the rat RIG was prepared and purified as described in the Materials and Methods section. Four groups of SD rats (12 rats/group) were inoculated, i.m. with $50 \times$ rat $\mathrm{LD}_{50} \mathrm{DRV}-\mathrm{Mexico}$. At $4 \mathrm{dpi}$, they were treated with AAV-CR57, AAV-EGFP, AAV-CR57+RIG (20 IU $/ \mathrm{kg})$, or AAV-EGFP+RIG $(20 \mathrm{IU} / \mathrm{kg})$ and then monitored daily for 3 weeks, and the flow chart of experimental design was as shown in Figure 7A. The survival rate was $60 \%$ in rats treated with AAV-CR57 and $50 \%$ in those treated with AAV-CR57+RIG. However, all rats treated with AAV-EGFP or AAV-EGFP+RIG succumbed to rabies by 18 dpi (Figure 7B). Moreover, the rabies symptoms (including weight loss, hind limb ataxia, hind limb paralysis, and paralysis) of the AAV-EGFP or AAV-EGFP+RIG inoculated rat appeared at $5 \mathrm{dpi}$ and became exacerbated until death at $18 \mathrm{dpi}$, while five of the rats inoculated with AAV-CR57 or AAV-CR57+RIG displayed mild symptoms which occurred at 6 dpi and recovered from 9 to $13 \mathrm{dpi}$ (Figure 7C). These data indicated that intrathecal inoculation with RIG alone had no obvious therapeutic effect in the RABV infected rats at $4 \mathrm{dpi}$, nor did it have any therapeutic benefit over AAV-CR57 administration alone.

Furthermore, the rat brains were collected for viral quantification and IHC analysis at $12 \mathrm{dpi}(n=3)$. IHC analysis showed that no RABV-P-positive cells were observed in the cerebrum, cerebellum, or brainstem of rats in the AAV-CR57 group. In contrast, significantly more RABV-P-positive cells were observed in the AAV-EGFP group (Figure 7D). The viral protein in the rat brains was further determined by Western blotting, and no RABV $\mathrm{N}$ protein was detected in 


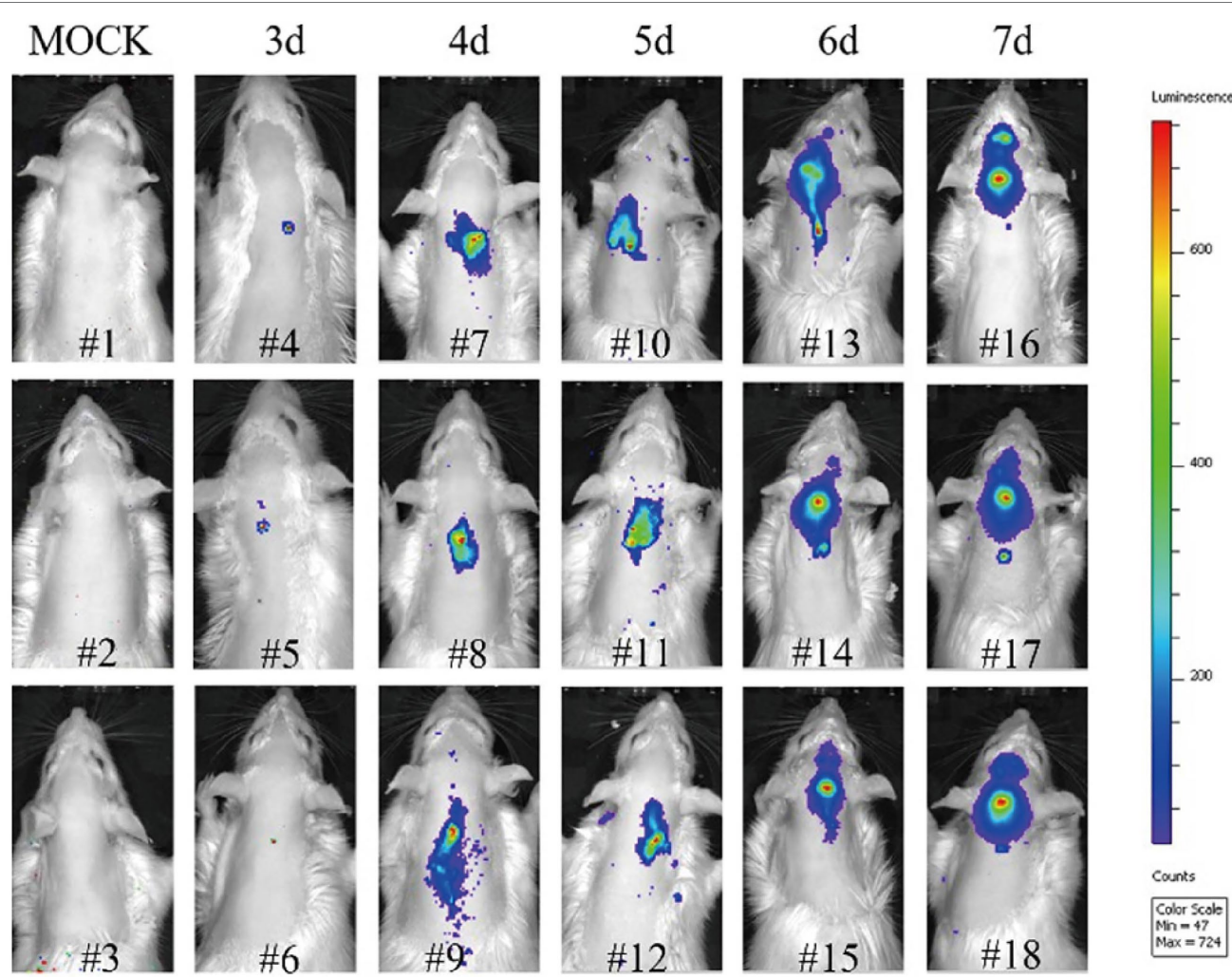

FIGURE 6 | The migration dynamics of RABV post i.m. infection in a rat model. Eighteen 6-week-old Sprague-Dawley (SD) rats were randomly divided into six groups, with three rats in each group. Five groups of rats were i.m. inoculated with $50 \times$ rat $L D_{50}$ RABV-teLuc, and the mock group was i.m. inoculated with the same volume of DMEM. During 3-7 dpi, one of the five groups of infected rats was taken every other day for intrathecal injection with $0.3 \mu \mathrm{mol}$ DTZ per rat. The mock group was inoculated with $0.3 \mu \mathrm{mol}$ DTZ per rat. Five minutes after injection with DTZ, the rats in each group were imaged by an IVIS Lumina III.

the brains of rats treated with AAV-CR57, while RABV $\mathrm{N}$ protein was detected in the brains of rats treated with AAV-EGFP (Figure 7E). Collectively, these results indicated that AAV-CR57 could increase the survivor ratio through intrathecal inoculation.

\section{DISCUSSION}

Several limitations still exist for the timely clearance of RABV in the CNS. Early detection of RABV using traditional methods remains difficult as the virus replicates relatively slowly before invading the brain. Delivery of VNAs to the CNS, due to the protection of the $\mathrm{BBB}$, presents another obstacle for timely neutralization of RABV. This study investigated the efficacy of AAVs expressing anti-RABV antibodies for preexposure and postexposure prophylaxis of rabies in rodent models.

Mild clinical symptoms of rabies such as weight loss could begin to appear at 6 or $7 \mathrm{dpi}$ in RABV-infected mice (Tian et al., 2017). However, RABV had already entered into the brain by that time (Tian et al., 2017), and the initiation of delivery of AAV-expressing RVNA may have been too late. Early diagnosis allows for the timely initiation of appropriate delivery and increases the chances of recovery. Bioluminescence imaging showed a positive viral signal in the brains of infected rats from 6 to $7 \mathrm{dpi}$, whereas the viral signal was observed in the spinal cords of infected rats at $4 \mathrm{dpi}$ (Figure 6). Combining the current methods with advanced detection techniques, such as RPA-CRISPR (Ren et al., 2021a), could improve therapeutic efficiency.

As indicated by the imaging results, RABV was presented in the spinal cords of the infected rats by $4 \mathrm{dpi}$ and had invaded the brain at $6 \mathrm{dpi}$ (Figure 6). Thus, there is a short window (approximately 2 days) during which time treatment can be initiated to interfere with RABV progression into the brain. According to our results, $70 \%$ survival rate was observed in $\mathrm{RABV}$-infected mice that were intracerebrally inoculated with AAV-CR57 at 4 dpi. However, administration with AAV-CR57 at 5 and 6 dpi did not enhance the survival rate (Figure 4D) because it usually took 2-3 days to express enough VNA to neutralize RABV after intrathecal delivery of AAV-CR57 (Figures 1D,E). In this situation, the expression of VNA in the mouse brain could not keep up with the speed of viral transmission, causing a reduction in the survival ratio. Thus, the delivery of AAV expressing VNA to the CNS no later than $4 \mathrm{dpi}$ is necessary for a therapeutic effect in RABVinfected mice. Notably, AAV-CR57 did not affect survival by i.v. or i.n. administration (Figures 4B,C). Most likely, only a small proportion of AAV-CR57 could pass through the BBB 


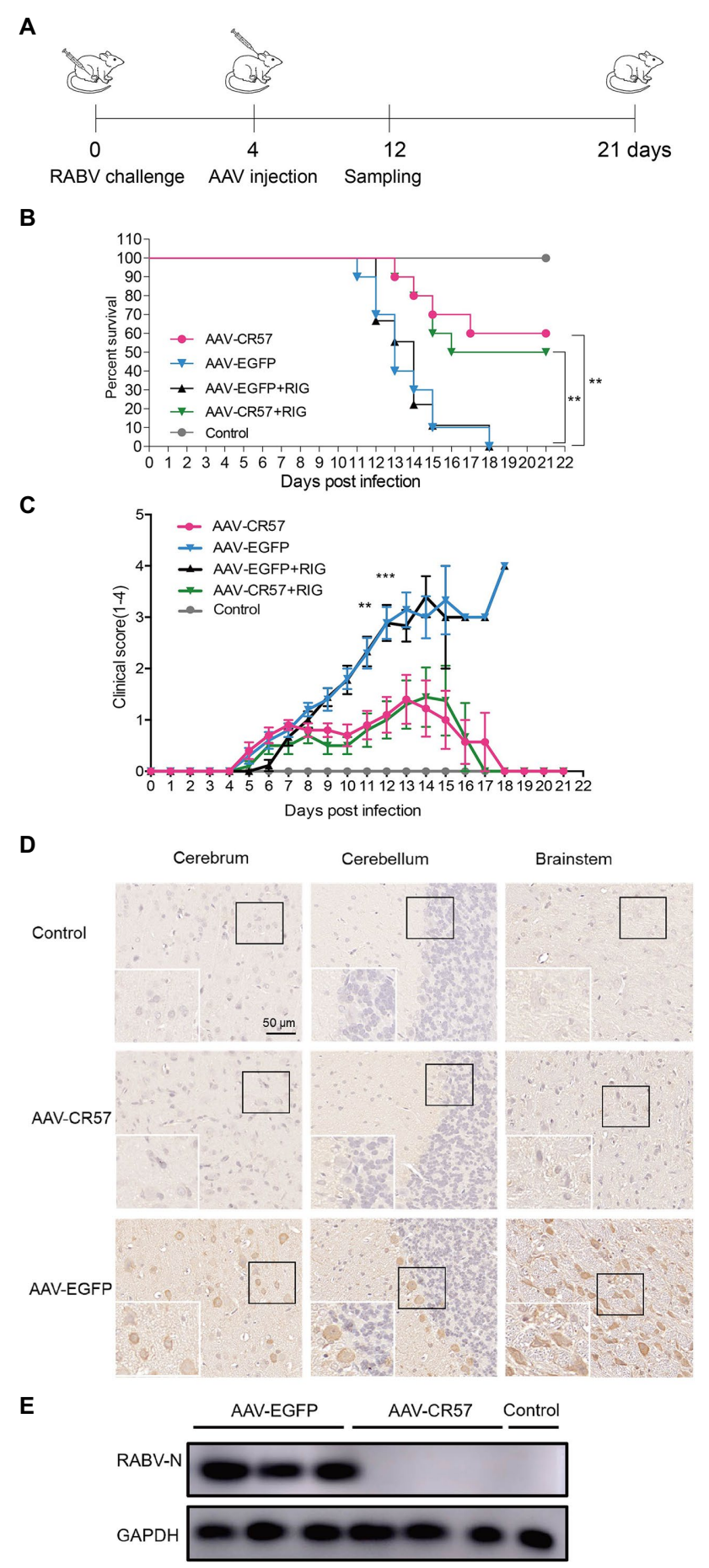

FIGURE 7 | Postexposure prophylaxis with AAV-CR57 for DRV-infected rats. (A) Flow chart of the therapeutic experiment of AAV-CR57 in a rat model. Groups of 6-week-old female SD rats $(n=10)$ were i.m. inoculated with $50 \times$ rat $L D_{50}$ DRV and intrathecally immunized with $4 \times 10^{12}$ vector genome of AAVs or together with $20 \mathrm{IU} / \mathrm{kg}$ rabies immune globulin (RIG) at the indicated time points post-inoculation. The mock group was i.m. inoculated with the same volume of DMEM and intrathecally immunized with the same volume of DMEM at the indicated time points post-inoculation. Survival ratio (B) and clinical score (C) were monitored once daily for 3 weeks (0: no apparent

(Continued)
FIGURE 7 | changes; 1: weight loss; 2: hind limb ataxia; 3: hind limb paralysis; and 4: paralysis). At $12 \mathrm{dpi}$, the brains were collected. Half of the brain was fixed, paraffin-embedded, sectioned, and analyzed by immunohistochemistry with antibodies against RABV-P (D). The other half of the brain was homogenized and analyzed by Western blotting (E). Detailed information about RIG was described in Production and Purification of Rat RIG section. ${ }^{\star \star} p<0.01 ;{ }^{\star \star \star} p<0.001$.

post i.v. or i.n. administration due to the protection of BBB. Therefore, intracerebral inoculation is the best strategy for AAV-CR57 dilvery in a mouse model.

It is not practical to inoculate AAV-CR57 into a human via intracerebral route. Thus, we evaluate the therapeutic effect of AAV-CR57 in a rat model via intrathecal inoculation. To supply VNA during the incubation period after inoculation with AAV-CR57, we injected AAV-CR57 together with rat-derived RIG into the CSF via intrathecal inoculation. Notably, a dose of RIG at $20 \mathrm{IU} / \mathrm{kg}$ body weight is typically recommended by the WHO for postexposure prophylaxis of rabies, and RIG is administered at the site of the bite(s) (World Health Organization, 2018). Unfortunately, our results suggested that there was no obvious difference between AAV-CR57 and AAV-CR57+RIG administration. According to a previous study, IgG was eliminated from the rat CSF by bulk flow at a half-life of approximately $47 \mathrm{~min}$ and a clearance of approximately $29 \mathrm{ml} / \mathrm{day} / \mathrm{kg}$. The eliminated IgG was transferred from the CSF into the blood circulation within $24 \mathrm{~h}$ after ICV dosing (Noguchi et al., 2017). We speculate that the short half-life of RIG in CSF might impede its neutralization effect. Before the VNA expression of AAV-CR57, the virus in the spinal cord was not effectively neutralized because the RIG did not remain in the CSF long enough after a single-dose injection.

The gene sequences of two well-known RABV-specific neutralizing antibodies, CR57, and CR4098, were cloned into AAVs and tested in vitro and in vivo. These two antibodies have been well-studied in animal models and have shown potential as an alternative to RIG in postexposure prophylaxis of rabies (Franka et al., 2017). However, we found that 8 weeks after i.m. administration of the $10^{12}$ vector genome, the VNA titer of AAV-CR4098-immunized mice was only $0.5 \mathrm{IU} / \mathrm{ml}$ compared with $40 \mathrm{IU} / \mathrm{ml}$ for the AAV-CR57-immunized mice (Figure 2A). Only AAV-CR57 generated a protective level of VNA in the serum and brain tissue after i.c. administration of the $10^{12} \mathrm{AAV}$ vector into mouse brains (Figure 4A). It is not currently understood why AAV-CR4098 generates such low VNA titers compared with AAV-CR57. Newly developed mAbs such as RVC20 and RVC58 were found to have a higher potency than CR57 and CR4098 (De Benedictis et al., 2016; de Melo et al., 2020; Hellert et al., 2020). Combined utilization of these mAbs may improve the effectiveness of postexposure prophylaxis.

Due to the complicated structure of the CNS, timely clearance of the most neurotropic viruses in the CNS is still a major challenge. Researchers have attempted to develop antiviral drugs and antibodies, and even new materials against neurotropic viruses (Lofano et al., 2018; Ren et al., 2021b). However, some 
defects limit the efficacy of these agents, especially the obstruction of the BBB. This study demonstrated that AAV-CR57 is a practical strategy for preexposure and postexposure prophylaxis of rabies in the rodent model. Thus, this strategy can potentially be applicable for other infectious diseases caused by neurotropic pathogens.

\section{DATA AVAILABILITY STATEMENT}

The original contributions presented in the study are included in the article/supplementary material, further inquiries can be directed to the corresponding authors.

\section{ETHICS STATEMENT}

The animal study was reviewed and approved by the Scientific Ethics Committee of Huazhong Agricultural University.

\section{REFERENCES}

Appolinario, C. M., and Jackson, A. C. (2015). Antiviral therapy for human rabies. Antivir. Ther. 20, 1-10. doi: 10.3851/IMP2851

Bakker, A. B., Marissen, W. E., Kramer, R. A., Rice, A. B., Weldon, W. C., Niezgoda, M., et al. (2005). Novel human monoclonal antibody combination effectively neutralizing natural rabies virus variants and individual in vitro escape mutants. J. Virol. 79, 9062-9068. doi: 10.1128/JVI.79.14.9062-9068.2005

Basgoz, N., and Frosch, M. (1998). Case records of the Massachusetts general hospital: a 32-year-old woman with pharyngeal spasms and paresthesias after a dog bite. N. Engl. J. Med. 339, 105-112. doi: 10.1056/ NEJM199807093390208

Charlton, K. M., and Casey, G. A. (1981). Experimental rabies in skunks: persistence of virus in denervated muscle at the inoculation site. Can. J. Comp. Med. 45, 357-362.

Chen, Z., Zhou, M., Gao, X., Zhang, G., Ren, G., Gnanadurai, C. W., et al. (2013). A novel rabies vaccine based on a recombinant parainfluenza virus 5 expressing rabies virus glycoprotein. J. Virol. 87, 2986-2993. doi: 10.1128/ JVI.02886-12

De Benedictis, P., Minola, A., Rota Nodari, E., Aiello, R., Zecchin, B., Salomoni, A., et al. (2016). Development of broad-spectrum human monoclonal antibodies for rabies post-exposure prophylaxis. EMBO Mol. Med. 8, 407-421. doi: 10.15252/emmm.201505986

de Melo, G. D., Sonthonnax, F., Lepousez, G., Jouvion, G., Minola, A., Zatta, F., et al. (2020). A combination of two human monoclonal antibodies cures symptomatic rabies. EMBO Mol. Med. 12:e12628. doi: 10.15252/emmm.202012628

Dietzschold, B., Morimoto, K., Hooper, D. C., Smith, J. S., Rupprecht, C. E., and Koprowski, H. (2000). Genotypic and phenotypic diversity of rabies virus variants involved in human rabies: implications for postexposure prophylaxis. J. Hum. Virol. 3, 50-57.

Flotte, T. R., Afione, S. A., Conrad, C., McGrath, S. A., Solow, R., Oka, H., et al. (1993). Stable in vivo expression of the cystic fibrosis transmembrane conductance regulator with an adeno-associated virus vector. Proc. Natl. Acad. Sci. U. S. A. 90, 10613-10617.

Fooks, A. R., Banyard, A. C., Horton, D. L., Johnson, N., McElhinney, L. M., and Jackson, A. C. (2014). Current status of rabies and prospects for elimination. Lancet 384, 1389-1399. doi: 10.1016/S0140-6736(13)62707-5

Franka, R., Carson, W. C., Ellison, J. A., Taylor, S. T., Smith, T. G., Kuzmina, N. A., et al. (2017). In vivo efficacy of a cocktail of human monoclonal antibodies (CL184) against diverse north american bat rabies virus variants. Trop. Med. Infect. Dis. 2:48. doi: 10.3390/tropicalmed2030048

Goudsmit, J., Marissen, W. E., Weldon, W. C., Niezgoda, M., Hanlon, C. A., Rice, A. B., et al. (2006). Comparison of an anti-rabies human monoclonal

\section{AUTHOR CONTRIBUTIONS}

FH and LZ: conceptualization, methodology, validation, and visualization. FH: formal analysis. FH, MR, JP, HM, BS, QW, and BC: investigation. LZ: resources and supervision. $\mathrm{FH}$ and MR: data curation. FH and RY: writing - original draft preparation. FH, MZ, and LZ: writing - review and editing. HZ and LZ: project administration. ZF and LZ: funding acquisition. All authors contributed to the article and approved the submitted version.

\section{FUNDING}

This research was supported by the National Natural Science Foundation of China (31872451 to LZ; 31720103917 and 31872452 to ZF). However, the funders had no role in study design, data collection, analysis, decision to publish, or manuscript preparation.

antibody combination with human polyclonal anti-rabies immune globulin. J. Infect. Dis. 193, 796-801. doi: 10.1086/500470

Hellert, J., Buchrieser, J., Larrous, F., Minola, A., de Melo, G. D., Soriaga, L., et al. (2020). Structure of the prefusion-locking broadly neutralizing antibody RVC20 bound to the rabies virus glycoprotein. Nat. Commun. 11:596. doi: 10.1038/s41467-020-14398-7

Huang, Y., Chen, Z., Huang, J., Fu, Z., and He, B. (2015). Parainfluenza virus 5 expressing the $\mathrm{G}$ protein of rabies virus protects mice after rabies virus infection. J. Virol. 89, 3427-3429. doi: 10.1128/JVI.03656-14

Jackson, A. C. (2003). Rabies virus infection: an update. J. Neurovirol. 9, 253-258. doi: 10.1080/13550280390193975

Katz, I. S. S., Guedes, F., Fernandes, E. R., and Dos Ramos Silva, S. (2017). Immunological aspects of rabies: a literature review. Arch. Virol. 162, 3251-3268. doi: 10.1007/s00705-017-3484-0

Kelly, R. M., and Strick, P. L. (2000). Rabies as a transneuronal tracer of circuits in the central nervous system. J. Neurosci. Methods 103, 63-71. doi: 10.1016/S0165-0270(00)00296-X

Kuzmin, D. A., Shutova, M. V., Johnston, N. R., Smith, O. P., Fedorin, V. V., Kukushkin, Y. S., et al. (2021). The clinical landscape for AAV gene therapies. Nat. Rev. Drug Discov. 20, 173-174. doi: 10.1038/d41573-021-00017-7

Liu, C., Li, J., Yao, Q., Gao, Z., Cheng, Y., Zhou, M., et al. (2020). AAVexpressed $\mathrm{G}$ protein induces robust humoral and cellular immune response and provides durable protection from rabies virus challenges in mice. Vet. Microbiol. 242:108578. doi: 10.1016/j.vetmic.2020.108578

Lofano, G., Gorman, M. J., Yousif, A. S., Yu, W.-H., Fox, J. M., Dugast, A.-S., et al. (2018). Antigen-specific antibody fc glycosylation enhances humora immunity via the recruitment of complement. Sci. Immunol. 3:eaat7796. doi: 10.1126/sciimmunol.aat7796

Luo, Z., Li, Y., Zhou, M., Lv, L., Wu, Q., Chen, C., et al. (2019). Toll-like receptor 7 enhances rabies virus-induced humoral immunity by facilitating the formation of germinal centers. Front. Immunol. 10:429. doi: 10.3389/ fimmu.2019.00429

Marissen, W. E., Kramer, R. A., Rice, A., Weldon, W. C., Niezgoda, M., Faber, M., et al. (2005). Novel rabies virus-neutralizing epitope recognized by human monoclonal antibody: fine mapping and escape mutant analysis. J. Virol. 79, 4672-4678. doi: 10.1128/JVI.79.8.4672-4678.2005

Martinez-Navio, J. M., Fuchs, S. P., Pantry, S. N., Lauer, W. A., Duggan, N. N., Keele, B. F., et al. (2019). Adeno-associated virus delivery of anti-HIV monoclonal antibodies can drive long-term virologic suppression. Immunity 50, 567.e565-575.e565. doi: 10.1016/j.immuni.2019.02.005

Meng, Q., Zhang, B., and Zhang, C. (2013). A new method of measuring the titrator of recombinant gland-related virus genomes. J. Bioeng. 29, 235-242. doi: $10.13345 /$ j.cjb.2013.02.008 
Naso, M. F., Tomkowicz, B., Perry, W. L. 3rd, and Strohl, W. R. (2017). Adeno-associated virus (AAV) as a vector for gene therapy. BioDrugs 31, 317-334. doi: 10.1007/s40259-017-0234-5

Noguchi, Y., Kato, M., Ozeki, K., and Ishigai, M. (2017). Pharmacokinetics of an intracerebroventricularly administered antibody in rats. MAbs 9, 1210-1215. doi: 10.1080/19420862.2017.1345834

Pei, J., Huang, F., Wu, Q., Luo, Z., Zhang, Y., Ruan, J., et al. (2019). Codon optimization of $\mathrm{G}$ protein enhances rabies virus-induced humoral immunity. J. Gen. Virol. 100, 1222-1233. doi: 10.1099/jgv.0.001299

Rabinowitz, J., Chan, Y. K., and Samulski, R. J. (2019). Adeno-associated virus (AAV) versus immune response. Viruses 11:102. doi: 10.3390/v11020102

Ren, M., Mei, H., Zhou, J., Zhou, M., Han, H., and Zhao, L. (2021a). Early diagnosis of rabies virus infection by RPA-CRISPR techniques in a rat model. Arch. Virol. 166, 1083-1092. doi: 10.1007/s00705-021-04970-x

Ren, M., Zhou, J., Song, Z., Mei, H., Zhou, M., Fu, Z. F., et al. (2021b). Aptamer and RVG functionalized gold nanorods for targeted photothermal therapy of neurotropic virus infection in the mouse brain. Chem. Eng. J. 411:128557. doi: 10.1016/j.cej.2021.128557

Samaranch, L., Pérez-Cañamás, A., Soto-Huelin, B., Sudhakar, V., Jurado-Arjona, J., Hadaczek, P., et al. (2019). Adeno-associated viral vector serotype 9-based gene therapy for Niemann-pick disease type A. Sci. Transl. Med. 11:eaat3738. doi: 10.1126/scitranslmed.aat3738

Samaranch, L., Salegio, E. A., San Sebastian, W., Kells, A. P., Foust, K. D., Bringas, J. R., et al. (2012). Adeno-associated virus serotype 9 transduction in the central nervous system of nonhuman primates. Hum. Gene Ther. 23, 382-389. doi: 10.1089/hum.2011.200

Schnell, M. J., McGettigan, J. P., Wirblich, C., and Papaneri, A. (2010). The cell biology of rabies virus: using stealth to reach the brain. Nat. Rev. Microbiol. 8, 51-61. doi: 10.1038/nrmicro2260

Smith, S. P., Wu, G., Fooks, A. R., Ma, J., and Banyard, A. C. (2019). Trying to treat the untreatable: experimental approaches to clear rabies virus infection from the CNS. J. Gen. Virol. 100, 1171-1186. doi: 10.1099/jgv.0.001269

Sui, B., Chen, D., Liu, W., Wu, Q., Tian, B., Li, Y., et al. (2020). A novel antiviral IncRNA, EDAL, shields a T309 O-GlcNAcylation site to promote EZH2 lysosomal degradation. Genome Biol. 21:228. doi: 10.1186/ s13059-020-02150-9

Taghian, T., Marosfoi, M. G., Puri, A. S., Cataltepe, O. I., King, R. M., Diffie, E. B., et al. (2020). A safe and reliable technique for CNS delivery of AAV vectors in the cisterna magna. Mol. Ther. 28, 411-421. doi: 10.1016/j. ymthe.2019.11.012

Tian, D., Luo, Z., Zhou, M., Li, M., Yu, L., Wang, C., et al. (2016). Critical role of K1685 and K1829 in the large protein of rabies virus in viral pathogenicity and immune evasion. J. Virol. 90, 232-244. doi: 10.1128/ JVI.02050-15

Tian, B., Zhou, M., Yang, Y., Yu, L., Luo, Z., Tian, D., et al. (2017). Labattenuated rabies virus causes abortive infection and induces cytokine expression in astrocytes by activating mitochondrial antiviral-signaling protein signaling pathway. Front. Immunol. 8:2011. doi: 10.3389/fimmu.2017.02011
Ugolini, G., and Hemachudha, T. (2018). Rabies: changing prophylaxis and new insights in pathophysiology. Curr. Opin. Infect. Dis. 31, 93-101. doi: 10.1097/QCO.0000000000000420

Wang, Z. W., Sarmento, L., Wang, Y., Li, X. Q., Dhingra, V., Tseggai, T., et al. (2005). Attenuated rabies virus activates, while pathogenic rabies virus evades, the host innate immune responses in the central nervous system. J. Virol. 79, 12554-12565. doi: 10.1128/JVI.79.19.12554-12565.2005

Wang, H., Zhang, G., Wen, Y., Yang, S., Xia, X., and Fu, Z. F. (2011). Intracerebral administration of recombinant rabies virus expressing GM-CSF prevents the development of rabies after infection with street virus. PLoS One 6:e25414. doi: 10.1371/journal.pone.0025414

Willoughby, R. E. Jr., Tieves, K. S., Hoffman, G. M., Ghanayem, N. S., Amlie-Lefond, C. M., Schwabe, M. J., et al. (2005). Survival after treatment of rabies with induction of coma. N. Engl. J. Med. 352, 2508-2514. doi: 10.1056/NEJMoa050382

World Health Organization (2018). Rabies vaccines: WHO position paper, April 2018 - recommendations. Vaccine 36, 5500-5503. doi: 10.1016/j.vaccine.2018.06.061

Yamaoka, S., Ito, N., Ohka, S., Kaneda, S., Nakamura, H., Agari, T., et al. (2013). Involvement of the rabies virus phosphoprotein gene in neuroinvasiveness. J. Virol. 87, 12327-12338. doi: 10.1128/JVI.02132-13

Yeh, H. W., Karmach, O., Ji, A., Carter, D., Martins-Green, M. M., and Ai, H. W. (2017). Red-shifted luciferase-luciferin pairs for enhanced bioluminescence imaging. Nat. Methods 14, 971-974. doi: 10.1038/nmeth.4400

Zeiler, F. A., and Jackson, A. C. (2016). Critical appraisal of the Milwaukee protocol for rabies: This failed approach should be abandoned. Can. J. Neurol. Sci. 43, 44-51. doi: 10.1017/cjn.2015.331

Zhang, G., Wang, H., Mahmood, F., and Fu, Z. F. (2013). Rabies virus glycoprotein is an important determinant for the induction of innate immune responses and the pathogenic mechanisms. Vet. Microbiol. 162, 601-613. doi: 10.1016/j. vetmic.2012.11.031

Conflict of Interest: The authors declare that the research was conducted in the absence of any commercial or financial relationships that could be construed as a potential conflict of interest.

Publisher's Note: All claims expressed in this article are solely those of the authors and do not necessarily represent those of their affiliated organizations, or those of the publisher, the editors and the reviewers. Any product that may be evaluated in this article, or claim that may be made by its manufacturer, is not guaranteed or endorsed by the publisher.

Copyright (C) 2021 Huang, Ren, Pei, Mei, Sui, Wu, Chai, Yang, Zhou, Fu, Zhou and Zhao. This is an open-access article distributed under the terms of the Creative Commons Attribution License (CC BY). The use, distribution or reproduction in other forums is permitted, provided the original author(s) and the copyright owner(s) are credited and that the original publication in this journal is cited, in accordance with accepted academic practice. No use, distribution or reproduction is permitted which does not comply with these terms. 